\title{
Is adaptation success a flawed concept?
}

Lisa Dilling, * Environmental Studies Program and Cooperative Institute for Research in Environmental Sciences, University of Colorado, Boulder, Colorado, USA

Anjal Prakash, TERI - School of Advanced Studies, Hyderabad, India

Zinta Zommers, UN Office for Disaster Risk Reduction, Bonn, Germany

Farid Ahmad, International Center for Integrated Mountain Development (ICIMOD), Kathmandu, Nepal

Nuvodita Singh, School of International and Public Affairs, Columbia University, New York

Sara De Wit, Institute for Science, Innovation and Society (InSIS), University of Oxford, Oxford, UK

Johanna Nalau, Cities Research Institute (CRI) and School of Environment and Science, Griffith University, Brisbane, Australia

Meaghan Daly, Department of Environmental Studies, University of New England, Biddeford, Maine, USA

Kerry Bowman, University of Toronto, Toronto, Canada

* Corresponding author, Idilling@colorado.edu

STANDFIRST PARAGRAPH: The Paris Agreement established a global goal on adaptation and invites parties to review the effectiveness of adaptation actions. However, the measurement of adaptation success remains elusive. Focusing on the capabilities of households and governments to pursue a range of adaptation futures provides a more robust foundation.

The Paris Agreement established a global goal on adaptation (Article 7, para. 1) and invites Parties to "review the adequacy and effectiveness of adaptation" in a global stocktake (Article 7, para 14c). However, creating universally applicable measures of adaptation success remains elusive given that most adaptation projects are implemented at the local level, and start from wildly differing baseline conditions. Further, the adaptation process is never truly "finished" in a changing, evolving climate ${ }^{1}$. Berrang-Ford et al. ${ }^{2}$ propose tracking government adaptation policy instruments as a way to assess progress. However, these and other approaches do not address what constitutes "success", focusing instead on government planning, or how vulnerability is changing-- leaving open the question of vulnerability of whom, 
to what, and who decides. In this Commentary, we propose that the focus should instead be on bolstering and measuring the capabilities of individuals and institutions; capabilities which are necessary to pursue a range of resilient futures and adaptation goals.

We know from past experience in other fields that developing metrics to define progress or success can be challenging. While technologies of assessment might appear apolitical, they in fact privilege certain worldviews and processes over others. ${ }^{3}$ Measuring adaptation success poses particular challenges:

\section{There is no single definition of adaptation success.}

Unlike mitigation, there is no universal unit of measurement for adaptation. Adaptation success has many meanings--local context determines what must be adapted to, as well as who must do the adapting, and whether actions at other scales are complementary or not ${ }^{1,2}$. Despite the laudable goals of the UNFCCC, a common understanding of, or way to verify, "effectiveness" simply does not exist ${ }^{1}$. The incomplete and fragmented nature of the understanding of adaptation and the long time periods over which adaptation effectiveness must be judged all pose challenges to tracking. Even for developed countries, adaptations that worked well in the last century may be maladaptive by 2050 or earlier. For example, the recent de-poldering of parts of the Netherlands that had been previously protected from flooding for over 1000 years demonstrates a shift from thinking that adaptations should "control" the river to instead making "room for the river" 4 .

\section{People have different, and evolving views of risk changing, risk perspectives and tolerances}

Different perceptions of adaptation success may stem from differing perceptions of what constitutes a risk and whether or how a risk should be mitigated. For example, water users in Colorado, USA have very different views about how to manage a finite water supply, and for some, new regulations or innovations implemented in the name of adaptation that affect property rights might be perceived as a greater risk to livelihoods than climate change ${ }^{5}$. Risk may also be tolerated for the gain and livelihood that it provides. Char lands in Bangladesh rivers are flooded every year, but communities come back and reclaim the land soon after the flood water recedes ${ }^{6}$. Given the multi-level governance nature of adaptation, there are also different perceptions among actors at local, regional, state and national scales as to which risks are most urgent ${ }^{7}$. Even within a single urban area there are significant differences in how resilience is defined, and what constitutes a legitimate path forward ${ }^{8}$.

\section{Who gets to define what is measured, matters.}


Both adaptation interventions and measuring their success are inevitably shaped by and embedded in systems of power that deserve critical scrutiny. Power asymmetries are becoming particularly salient in the context of North-South relations and the political effects of adaptation discourse in the Global South have remained largely invisible in scholarly debate ${ }^{9}$. A global stocktake process for climate adaptation will likely be driven by those with the capacity to participate at the national and international level, and likely thus obscure the views of local actors with less power and especially vulnerable groups ${ }^{9,10}$. Already, within-country rural residents' needs and local institutions are not well represented within National Adaptation Programmes of Action (NAPAs) ${ }^{11}$. Finally, in the context of development aid, results-based management, which seeks to define clear goals and demonstrate evidence of success, can lead to the funding of the easiest projects to implement and measure from the perspective of donors, and in the process leave the most vulnerable completely without assistance ${ }^{12}$.

\section{The path forward}

Despite these critical measurement complications, an urgent mandate exists to move forward with adaptation worldwide. We suggest two strands of complementary efforts:

\section{Empower local people to create metrics that matter to them.}

Metrics must be defined by and be meaningful to the people and organizations on the ground ${ }^{13}$. As Bockstael and Berkes express, "people need to be actively involved in planning their future and not be the passive recipients of programs designed by others" ${ }^{14}$. The process of tracking change may be an opportunity to create authentic dialogue about what societies value and whose interests are represented. Efforts can start with questions such as, what matters to local well-being and what are individual and community aspirations? What are the most important measures that capture local aspirations, significant impacts, social frameworks, and economic opportunities? Jones has described how researchers and the households they study can differ on how they define resilience and the way it should be evaluated-- and that measuring (through surveys, for example) the perspectives of individuals on their own situation (e.g. ability to recover from an adverse event) provides a valuable way of documenting what does and does not work to build resilience-the same is likely true for adaptation ${ }^{15}$. While this might make the comparability of adaptation more challenging across contexts, it could facilitate more meaningful comparisons to be made within contexts and across time. Finally, creative quantitative and qualitative methods, including storytelling ${ }^{16}$, participatory video and photovoice ${ }^{17}$, and collaborative community "atlases of community change" ${ }^{18}$ could be used to measure local perspectives on adaptation.

In the interest of equity, it will be necessary to take time to hear many different voices, including the most vulnerable ${ }^{19}$. This means that metrics need to address the socio-political 
context and include questions about the transparency of power dynamics, understanding who will benefit, and who has a voice in talking about adaptation success. While national governments may select what to report in UNFCCC adaptation communications, and thus may have some freedom to define metrics, they should also involve and include sub-national and local perspectives, including non-government actors. The Marrakech Partnership for Global Climate Action is working to involve a greater range of actors but efforts should be further extended.

\section{Focus on building long term adaptive capacity and flexibility.}

Some of the most important critical adaptation-related needs may not directly relate to climate. Instead of debating adaptation success, focus should extend to building and measuring capabilities that empower communities in the face of climate change. This builds on the work of Amartya Sen, who argued that development is the freedom to achieve well-being ${ }^{20}$. Rather than imposing a standardized outcome, individuals must be empowered to pursue the lives, or in this case, the adaptation outcomes, they have reason to value. Capabilities critical to effectively respond to climate change may include access to increased education, which is necessary to build diversified livelihoods; access to health care, necessary to respond to new health risks; access to technology, increasingly necessary for communication and information access; strengthened social support necessary to prepare for and respond to shocks; and good governance necessary to ensure services are delivered. Capabilities can directly support adaptation: for example, according to Striessnig et al. female education may be the single most important socio-economic factor associated with reduced vulnerability to disasters ${ }^{21}$. Some processes and international agreements have already outlined metrics of success that may support the building of these capabilities (e.g. the UN Sustainable Development Goals, The Sendai Framework, and the Convention on Biological Diversity), which in turn lay the foundation needed to support adaptation efforts as climate change unfolds. Efforts of the scientific and international communities would be better spent understanding how to build, support, and measure capabilities of communities, and how those capabilities in turn enable adaptive capacity for climate change, rather than trying to develop a universal definition of adaptation success.

In summary, let us rethink the idea of reporting on or measuring adaptation success. Rather, let us focus on understanding and articulating how the capabilities approach, driven by the needs and values of local communities and especially the most vulnerable, can be harnessed to provide increasing adaptive capacity for the future. There is value in accelerating the sharing of experiential and research knowledge across networks and scales. However caution must be exercised in promoting any particular definition or metric for adaptation success, as this will undoubtedly privilege some views and exclude others, and not necessarily 
lead to the needed changes to support adaptation. The adaptation community could instead invest in understanding how other metrics already in place can be harnessed and leveraged to support adaptive capacity. How do improvements in capabilities improve adaptive capacity for climate? Do increasing capabilities increase flexibility, reduce it, or otherwise change the nature of the vulnerability? What are the risk tradeoffs that communities must grapple with when choosing between different adaptation strategies? These questions can only be answered by building processes that focus on empowering communities, linking resources across scales, and supporting effective communities of practice that accelerate the development of capabilities linked to adaptation questions in ways that are meaningful to specific contexts.

\section{Acknowledgements}

This comment evolved from a special session on adaptation success convened by the authors at Adaptation Futures 2018, the 5th International Climate Change Adaptation Conference in Cape Town. We thank the over 100 session participants from around the world, including participants from government agencies, donors, non-governmental organizations, students, humanitarian agencies, academics, policy-makers and members of civil society. LD acknowledges the support of NSF Grant No. 1354542. Anjal Prakash, Nuvodita Singh and Farid Ahmad's time was supported by the HI-AWARE project under Collaborative Adaptation Research Initiative in Africa and Asia (CARIAA) with financial support from the UK Government's Department for International Development and the International Development Research Centre, Ottawa, Canada. The views expressed in this work are those of the creators and do not necessarily represent those of the UK Government's Department for International Development, the International Development Research Centre, Canada or its Board of Governors, and are not necessarily attributable to their organizations. All responsibility for the content remains with the authors.

\section{References:}

${ }^{1}$ Tompkins, E. L., Vincent, K., Nicholls, R. J., \& Suckall, N. Wiley Interdisciplinary Reviews: Climate Change, 9(5), e545. (2018).

${ }^{2}$ Berrang-Ford, L., et al. Nature Climate Change, 9(6), 440-449. doi:10.1038/s41558-019-0490-0 (2019).

${ }^{3}$ Merry, S.E. Current Anthropology, 52(3): 83-95. (2011)

${ }^{4}$ Rijke, J., van Herk, S., Zevenbergen, C., \& Ashley, R. International Journal of River Basin Management, 10(4), 369-382. doi:10.1080/15715124.2012.739173 (2012). 
${ }^{5}$ McNeeley, S. M., \& Lazrus, H. Weather, Climate, and Society, 6(4), 506-519.

doi:10.1175/WCAS-D-13-00027.1 (2014).

${ }^{6}$ Lahiri-Dutt, K., \& Samanta, G. Dancing with the river: people and life on the chars of South Asia. (Yale University Press, New Haven, 2013).

${ }^{7}$ Nalau, J., Preston, B. L., \& Maloney, M. C. Environmental Science and Policy, 48, 89-98. doi:10.1016/j.envsci.2014.12.011 (2015).

${ }^{8}$ Borie, M., Pelling, M., Ziervogel, G., \& Hyams, K. Global Environmental Change, 54, 203-213. doi:10.1016/j.gloenvcha.2019.01.001 (2019).

${ }^{9}$ Klepp, S., \& Chavez-Rodriguez, L. A critical approach to climate change adaptation. Discourses, policies and practices. (Routledge, London \& New York, 2018).

${ }^{10}$ Eguavoen, I., Schulz, k., de Wit, S., Weisser, F. and Müller-Mahn, D. In

Leal Filho W. (Ed) Handbook of Climate Change Adaptation, pp. 1183-1198. (Springer: Berlin, Heidelberg 2015).

${ }^{11}$ Agrawal, A., \& Perrin, N. In N. Adger, I. Lorenzoni, \& K. O'Brien (Eds.), Adaptation to Climate Change: Thresholds, Values, Governance, pp. 350-367. (Cambridge University Press, Cambridge, UK 2009).

12 Krause, M. The good project: Humanitarian relief NGOs and the fragmentation of reason. (Chicago University Press, Chicago, USA 2014).

${ }^{13}$ Barnett, J., Lambert, S., \& Fry, I. Annals of the Association of American Geographers, 98(1), 102-119. (2008).

${ }^{14}$ Bockstael, E., \& Berkes, F. International Journal of the Commons, 11(2), 799-822. doi:10.18352/ijc.756 pp. 800. (2017).

${ }^{15}$ Jones, L. Wiley Interdisciplinary Reviews: Climate Change. doi:10.1002/wcc.552 (2018).

${ }^{16}$ Goldstein, B. E., Wessells, A. T., Lejano, R., \& Butler, W. Urban Studies, 52(7), 1285-1303. https://doi.org/10.1177/0042098013505653 (2015).

${ }^{17}$ O'Neill, S. J., \& Graham, S. Geo: Geography and Environment, 3(2), e00028. (2016).

${ }^{18}$ Crate, S. In A critical approach to climate change adaptation. Discourses, policies and practices. Klepp, S. \& L. Chavez-Rodriguez (eds.), pp. 241-255. (Routledge, London \& New York, 2018) 
${ }^{19}$ Pelling, M., \& Garschagen, M. Nature, 569(16 May), 327-329. (2019).

${ }^{20}$ Sen, A. Development as Freedom. (Oxford, Oxford University Press, 1999)

${ }^{21}$ Striessnig, E., W. Lutz, and A. G. Patt. Ecology and Society 18(1): 16.

http://dx.doi.org/10.5751/ES-05252-180116 (2013). 